\title{
Provider and Patient Characteristics of Medicare Beneficiaries Who Are High-Risk for COVID-19 Mortality
}

J Gen Intern Med 36(7):2189-90

DOI: $10.1007 / \mathrm{s} 11606-021-06857-8$

(c) Society of General Internal Medicine 2021

\section{INTRODUCTION}

The Medicare population comprises 60 million Americans, ${ }^{1}$ many of whom are the most vulnerable people susceptible to COVID-19 mortality. The National Academies of Sciences, Engineering and Medicine recommended targeting high-risk individuals including older individuals in the early stages of a national vaccine rollout. ${ }^{2}$ In this study, we identify Medicare beneficiaries at high risk for COVID-19 mortality, and characterize primary care providers who serve these beneficiaries.

\section{METHODS}

We identified Medicare beneficiaries at high risk for COVID19 mortality using a recently validated COVID-19 mortality risk scoring algorithm ${ }^{3}$ applied to Medicare data. The algorithm uses an individual's demographic data (age, race, gender, body mass index (BMI), and location-based measure of social deprivation), smoking status, and ten predisposing medical conditions to estimate COVID-19 mortality risk. Due to data limitations, we modified the risk algorithm to exclude the two data inputs: smoking and BMI. We applied this algorithm to the $20 \%$ sample of the 2018 Medicare claims dataset. The Medicare beneficiary summary file and the Chronic Conditions Warehouse data within the file provided the inputs for the algorithm except for the cancer variables and county-level Social Deprivation Index (SDI) quintile. Data on cancer in the calendar year was ascertained using Medicare outpatient claims. An individual's SDI quintile was ascertained using that individual's county and its corresponding SDI value. ${ }^{4}$ Beneficiaries who lacked Medicare Part B or were covered in a Medicare Advantage Plan were excluded.

We then estimated individual risk scores for each Medicare beneficiary. High-risk and very high-risk Medicare beneficiaries were identified respectively with risk scores that were greater than or equal to five times and ten times the average of the general population risk based on data from the National Health Interview Survey. ${ }^{5}$ We summarized beneficiaries'

Received December 15, 2020

Accepted April 26, 2021

Published online May 6, 2021 demographics, number of chronic conditions, and healthcare utilization. We also identified their primary care providers using outpatient claims. Primary care providers were approximated using the attending specialty codes. We then stratified coverage of beneficiaries by providers based on total beneficiary visits.

\section{RESULTS}

We calculated risk scores for approximately 5.5 million beneficiaries, among whom 1,891,599 were high-risk and 791,787 were very high-risk for COVID-19 mortality (Table 1). Highrisk Medicare beneficiaries were older, had more chronic conditions, and were greater utilizers of healthcare than the general Medicare population. These high-risk beneficiaries also had nearly 6.4 million outpatient visits with an estimated 20,889 unique primary care providers (Table 2). The top 1000 providers who had the most visits saw $45 \%$ of the high-risk beneficiaries. This coverage increases to nearly $70 \%$ for the top 5000 providers.

\section{DISCUSSION}

Medicare beneficiaries who were deemed high-risk for Covid mortality represented high frequency users of Medicare and medically complex patients. However, identifying these beneficiaries from the millions of other Medicare beneficiaries is a logistical challenge. Our study utilized claims data and a validated predictive algorithm to identify these patients. A similar approach could have been taken to prioritize health systems and primary care physicians caring for patients at highest risk to target allocation of vaccine supplies. This approach could have utilized electronic health records to identify specific high-risk Medicare beneficiaries to offer vaccination. Policymakers could then have supported these providers with additional resources to identify and outreach to high-risk patients.

Our study had several limitations. Given the urgency of the vaccination campaign, our algorithm was not immediately available to federal, state, and local governments to identify practices in time for vaccine distribution. Our study relied on claims data including chronic conditions indicators which may be less accurate than electronic health records. Lastly, the algorithm would need to be modified to match available data for it to run within health systems.

Primary care providers offer a distinct advantage over pharmacies for identification of high-risk beneficiaries because data on the risk factors, primary medical in nature, are more 
Table 1 Beneficiary Characteristics

\begin{tabular}{|c|c|c|c|}
\hline$\overline{\text { Variable }}$ & $\begin{array}{l}\text { Very high-risk } \\
\text { beneficiaries }^{1}\end{array}$ & $\begin{array}{l}\text { High-risk } \\
\text { Beneficiaries }^{2}\end{array}$ & $\begin{array}{l}\text { Full } \\
\text { Sample }\end{array}$ \\
\hline Total N & 791,787 & $1,891,599$ & $5,350,300$ \\
\hline \multicolumn{4}{|l|}{ Demographics } \\
\hline Male & 436,905 & 945,403 & $2,247,030$ \\
\hline Female & 354,882 & 946,196 & $3,103,270$ \\
\hline \multirow{2}{*}{\multicolumn{4}{|c|}{ Race }} \\
\hline & & & \\
\hline White & 529,712 & $1,381,303$ & $4,437,794$ \\
\hline Black & 191,254 & 350,577 & 506,005 \\
\hline Other & 9551 & 24,710 & 73,689 \\
\hline Asian & 14,830 & 32,849 & 86,401 \\
\hline Hispanic & 34,970 & 71,025 & 112,884 \\
\hline Native American & 8931 & 18,135 & 35,329 \\
\hline Unknown & 2539 & 13,000 & 98,199 \\
\hline $\begin{array}{l}\text { Number of } \\
\text { chronic conditions } \\
\text { (average) }\end{array}$ & 7.2 & 5.9 & 4.3 \\
\hline \multicolumn{4}{|l|}{ Healthcare utilization } \\
\hline $\begin{array}{l}\text { Outpatient visits } \\
\text { (average) }\end{array}$ & 16.9 & 14.1 & 10.9 \\
\hline $\begin{array}{l}\text { Inpatient stays } \\
\text { (average) }\end{array}$ & 0.14 & 0.09 & 0.06 \\
\hline $\begin{array}{l}\text { Inpatient length } \\
\text { of stay (average) }\end{array}$ & 1.3 days & 0.84 days & 0.56 days \\
\hline $\begin{array}{l}\text { Part D fills } \\
\text { (average) }\end{array}$ & 82.1 fills & 74.5 fills & 60.4 fills \\
\hline
\end{tabular}

${ }^{I}$ Very high-risk is defined as having ten times or greater predicted mortality from COVID-19 compared to the general population

${ }^{2}$ High-risk is defined as having five times or greater predicted mortality from COVID-19 compared to the general population

${ }^{3}$ Number of chronic conditions are based on the Chronic Conditions Warehouse data within the Medicare beneficiary file of which there are

27 possible chronic conditions

Table 2 Provider Characteristics

\begin{tabular}{|c|c|c|c|}
\hline Variable & $\begin{array}{l}\text { Very high-risk } \\
\text { Beneficiaries }^{1}\end{array}$ & $\begin{array}{l}\text { High-risk } \\
\text { beneficiaries }\end{array}$ & $\begin{array}{l}\text { Full } \\
\text { sample }\end{array}$ \\
\hline \multicolumn{4}{|c|}{ Primary care providers } \\
\hline $\begin{array}{l}\text { Number of } \\
\text { unique providers }\end{array}$ & 18,982 & 20,889 & 22,301 \\
\hline \multicolumn{4}{|c|}{ Visits by provider types } \\
\hline General practice & 99,858 & 211,543 & 486,612 \\
\hline Family practice & $1,104,124$ & $2,551,545$ & $6,554,153$ \\
\hline $\begin{array}{l}\text { Internal } \\
\text { medicine }\end{array}$ & $1,735,580$ & $3,554,824$ & $7,759,745$ \\
\hline $\begin{array}{l}\text { Geriatric } \\
\text { medicine }\end{array}$ & 27,131 & 85,250 & 443,196 \\
\hline $\begin{array}{l}\text { Preventive } \\
\text { medicine }\end{array}$ & 1056 & 2192 & 5340 \\
\hline \multicolumn{4}{|c|}{ Coverage of unique beneficiaries by high-frequency providers } \\
\hline Top 1000 & 358,639 & 830,584 & $2,296,716$ \\
\hline Providers & $(45.3 \%)$ & $(43.9 \%)$ & $(42.9 \%)$ \\
\hline \multicolumn{4}{|l|}{$\begin{array}{l}\text { Coverage of } \\
\text { unique } \\
\text { beneficiaries }\end{array}$} \\
\hline Top 5000 & 544,490 & $1,280,946$ & $3,534,199$ \\
\hline Providers & $(68.8 \%)$ & $(67.7 \%)$ & $(66.1 \%)$ \\
\hline \multicolumn{4}{|l|}{$\begin{array}{l}\text { Coverage of } \\
\text { unique } \\
\text { beneficiaries }\end{array}$} \\
\hline Top 10,000 & 566,097 & $1,336,932$ & $3,699,434$ \\
\hline Providers & $(71.5 \%)$ & $(70.6 \%)$ & $(69.1 \%)$ \\
\hline $\begin{array}{l}\text { Coverage of } \\
\text { unique }\end{array}$ & & & \\
\hline
\end{tabular}

${ }^{1}$ Very high-risk is defined as having ten times or greater predicted mortality from COVID-19 compared to the general population

${ }^{2}$ High-risk is defined as having five times or greater predicted mortality from COVID-19 compared to the general population accessible to primary providers than pharmacies. Pharmacies typically only assess medication histories and would miss important conditions that are not clearly associated with outpatient prescriptions. As vaccine rollout continues, and if new vaccinations become necessary in the pandemic, algorithms should be considered to maximize the match of vaccine supplies to those at highest risk.

Jeromie Ballreich, $\mathrm{PhD} \mathrm{MHS}^{1}$

Jin Jin, $P h D^{2}$

Prosenjit Kundu, $\mathrm{Ph} \mathrm{D}^{2}$

Nilanjan Chatterjee, $\mathrm{Ph} \mathrm{D}^{2,3}$

${ }^{1}$ Department of Health Policy \& Management, Johns Hopkins Bloomberg School of Public Health,

Baltimore, MD, USA

${ }^{2}$ Department of Biostatistics, Bloomberg School of Public Health, Johns Hopkins University,

Baltimore, MD, USA

${ }^{3}$ Department of Oncology, School of Medicine, Johns Hopkins University,

Baltimore, MD, USA

Corresponding Author: Jeromie Ballreich, PhD MHS; Department of Health Policy \& Management, Johns Hopkins Bloomberg School of Public Health, Baltimore, MD, USA (e-mail: jballre2@jhu.edu).

Author Contribution All authors contributed to the design, analysis, drafting and critical revision of this manuscript and all authors have approved the final version.

Funding This work was funded by Arnold Ventures (Ballreich).

\section{Declarations:}

Conflict of Interest: Dr. Ballreich receives research funding from Arnold Ventures. He also receives consulting fees from Monument Analytics, a health sciences consultancy. The authors report no other conflicts of interest.

Disclaimer: Dr. Ballreich had full access to the data and takes responsibility for the integrity of the data and the accuracy of the data analysis.

\section{REFERENCES}

1. CMS Fast Facts | CMS. Accessed November 16, 2020. https://www.cms. gov/Research-Statistics-Data-and-Systems/Statistics-Trends-and-Reports/CMS-Fast-Facts

2. National Academies of Sciences E. Framework for Equitable Allocation of COVID-19 Vaccine.; 2020. doi:10.17226/25917

3. Jin, J., Agarwala, N., Kundu, P., Harvey, B., Zhang, Y., Wallace, E., \& Chatterjee, N. (2020). Individual and community-level risk for COVID-19 mortality in the United States. Nature Medicine, 1-6.

4. Social Deprivation Index (SDI). Accessed November 29, 2020. https:// www.graham-center.org/rgc/maps-data-tools/sdi/social-deprivation-index.html

5. NHIS - National Health Interview Survey. Published November 3, 2020. Accessed November 29, 2020. https://www.cdc.gov/nchs/nhis/index. $\mathrm{htm}$

Publisher's Note: Springer Nature remains neutral with regard to jurisdictional claims in published maps and institutional affiliations. 